\title{
Device closure of atrial septal defects with the Amplatzer septal occluder: Safety and outcome in infants
}

Karim A. Diab, MD, ${ }^{\text {a }}$ Qi-Ling Cao, MD, ${ }^{a}$ Emile A. Bacha, MD, ${ }^{\text {b }}$ and Ziyad M. Hijazi, MD, MPHa

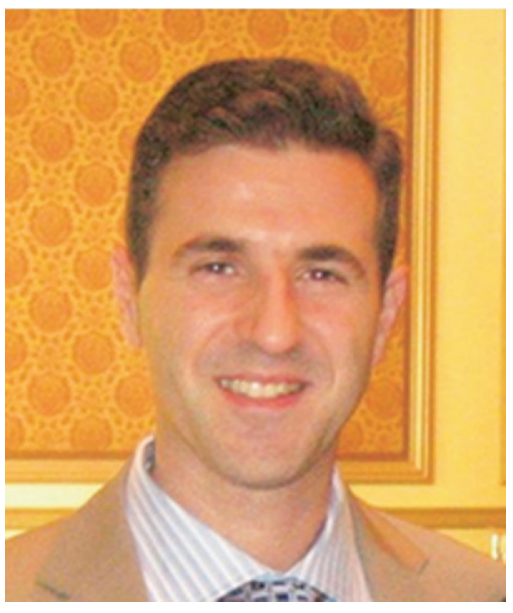

Dr Diab

Objective: Device closure of secundum atrial septal defects is sometimes needed in young children; however, little is known about the safety and outcome of this procedure in infants. In this study, the safety and efficacy of secundum atrial septal defect closure with the Amplatzer septal occluder (AGA Medical Corp, Golden Valley, Minn) was evaluated in patients less than 1 year of age.

Methods: Between July 1999 and September 2006, atrial septal defect closure with the Amplatzer septal occluder was attempted in 15 infants at our institution. The patients ranged in age from 0.5 to 11.9 months (mean \pm standard deviation; $8.2 \pm$ 3.7 months) in the percutaneous group and from 2.2 to 3.4 months $(2.9 \pm 0.6$ months) in the peratrial group. Their weights ranged from 3.8 to $8.3 \mathrm{~kg}(5.5 \pm 1.7 \mathrm{~kg})$ and from 3.0 to $4.0 \mathrm{~kg}(3.4 \pm 0.6 \mathrm{~kg})$ in each group, respectively. The indications for atrial septal defect closure were failure to thrive, significant chamber enlargement, hemodynamically significant shunts, and prehepatic transplantation. The size of the defect as measured by intracardiac echocardiography $(\mathrm{n}=3)$ or transesophageal echocardiography $(\mathrm{n}=12)$ ranged from 2.0 to $16 \mathrm{~mm}(8.0 \pm$ $4.4 \mathrm{~mm})$.

Results: The pulmonary/systemic flow ratio ranged from 1.0 to 9.0 (2.8 \pm 2.0$)$. The device was successfully placed in 14 of 15 infants. The size of the Amplatzer septal occluder device implanted ranged from 4 to $20 \mathrm{~mm}(10.1 \pm 4.3 \mathrm{~mm})$. It was percutaneously deployed in 11 of 14 patients and by the hybrid or peratrial approach (open chest off-pump) in 3 of 14 infants. In infants who had a successful attempt $(\mathrm{n}=14)$, the complete closure rates at 24 hours and 1 year were $86 \%$ and $100 \%$, respectively. In 3 of 15 infants, minor complications occurred: transient arrhythmias

From the Department of Pediatrics, University of Chicago Comer Children's Hospital, Pritzker School of Medicine, Chicago, $\mathrm{Ill}^{\mathrm{a}}$; and the Department of Cardiac Surgery, Boston Children's Hospital and Harvard Medical School, Boston, Mass. ${ }^{\text {b }}$

One author (Z.M.H.) was a consultant for AGA Medical Corporation until April 13, 2007, the company that manufactures the device, and received consulting and lecture fees.

Received for publication Oct 10, 2006; revisions received May 20, 2007; accepted for publication June 8, 2007.

Address for reprints: Ziyad M. Hijazi, MD, MPH, Director, Rush Center for Congenital and Structural Heart Disease, Rush University Medical Center, 1635 West Congress Parkway, Jones 770, Chicago, IL 60612 (E-mail: zhijazi@rush.edu).

J Thorac Cardiovasc Surg 2007;134:960-6

$0022-5223 / \$ 32.00$

Copyright (C) 2007 by The American Association for Thoracic Surgery

doi:10.1016/j.jtcvs.2007.06.018 $(\mathrm{n}=2)$ and blood transfusion $(\mathrm{n}=1)$. One patient had a major complication (vascular intimal injury with thrombosis of the inferior vena cava). One patient with Down syndrome died 6 weeks later of progressive pulmonary hypertension. The follow-up time ranged from 0.6 to 6.9 years ( $3.2 \pm 1.9$ years). At follow-up, clinical development and growth improved in all children with failure to thrive, and all ventilator-dependent children could be weaned shortly after closure of the atrial septal defect.

Conclusion: Device closure of atrial septal defects is an effective and fairly safe alternative to surgery in infants. Hybrid or peratrial closure is also an alternative to percutaneous closure in the very small infant.

$\mathrm{S}$ ecundum atrial septal defect (ASD) is a common congenital heart disease and accounts for approximately $6 \%$ to $10 \%$ of all congenital cardiac defects. ${ }^{1}$ Since 1976, when King and associates ${ }^{2}$ attempted the first transcatheter closure of a secundum ASD in humans, device closure has evolved significantly. The Amplatzer septal occluder (ASO) (AGA Medical Corp, Golden Valley, Minn) has become the most commonly used device. Previous reports have shown that it is easy to use and has a high success rate. ${ }^{3-6}$ The alleged advantages of percutaneous 


\section{Abbreviations and Acronyms \\ ASD $=$ atrial septal defect \\ ASO $=$ Amplatzer septal occluder \\ ICE = intracardiac echocardiography \\ TEE $=$ transesophageal echocardiography \\ VSD $=$ ventricular septal defect}

closure over surgical closure as shown by some studies in older children and adults include avoidance of cardiopulmonary bypass, decreased complication rates, shorter hospital stays, ${ }^{7,8}$ and greater cost-effectiveness. ${ }^{9}$

Although device closure is now a widely acceptable alternative to surgery in most patients with secundum ASD, it is still considered technically challenging in infants, with little known about its safety and feasibility in those less than 1 year of age. Previous studies involving device closure of secundum ASDs have included predominantly adults and older children, ${ }^{7,10,11}$ with no reports involving a large series of very young infants.

The aim of this study was to evaluate the feasibility, efficacy, and safety of device closure of secundum ASDs in infants using either the percutaneous or the hybrid (peratrial) approach.

\section{Materials and Methods \\ Device}

The ASO was used in all patients. A full description of this device has been reported previously. ${ }^{3,5}$ In brief, the device is made of 0.004- to 0.0075-inch nitinol wire. It consists of two expandable discs connected by a 4-mm long waist, the diameter of which corresponds to the size of the device, which is available in sizes ranging from 4 to $38 \mathrm{~mm}$.

\section{Patient Population}

Between July 1999 and September 2006, 15 infants (9 boys and 6 girls) underwent an attempt at closure of their secundum ASDs with the ASO by either the percutaneous or the hybrid technique. Routine informed consent was initially obtained from the parents before any kind of intervention and approval for chart review was obtained by the institutional review board. The infants ranged in age from 0.5 to 11.9 months (mean \pm standard deviation, $8.2 \pm$ 3.7 months) in the percutaneous group and from 2.2 to 3.4 months ( $2.9 \pm 0.6$ months) in the peratrial group. The weights ranged from 3.8 to $8.3 \mathrm{~kg}(6.0 \pm 1.4 \mathrm{~kg})$ and from 3.0 to $4.0 \mathrm{~kg}(3.4 \pm 0.6 \mathrm{~kg})$ in each group, respectively (Table 1). The indications for ASD closure included failure to thrive with significant chamber enlargement and/or hemodynamically significant shunts despite medical therapy in 11 patients. In 2 patients who were undergoing hepatic transplantation, device closure of a patent foramen ovale was performed to prevent any paradoxical emboli during inferior vena cava unclamping. Two other patients had significant chronic lung disease secondary to prematurity and were ventilator-dependent.

\section{Protocol}

All procedures were performed with the patient under general anesthesia with either continuous transesophageal (TEE, $\mathrm{n}=12$ ) or intracardiac echocardiographic (ICE, $\mathrm{n}=3$ ) guidance. The detailed protocol of percutaneous device closure has been reported previously., ${ }^{3,12}$ Full assessment of the defect and surrounding rims was performed. In the percutaneous cases, a hemodynamic assessment of the degree of left-to-right shunt was performed. Heparin was administered routinely in all patients. Angiography in the right upper pulmonary vein was performed to assess the size and location of the defect. Balloon sizing was not performed. The maximum size of the ASD was chosen as determined by echocardiography. Antibiotic prophylaxis was given during the procedure and then at 8 hours and 16 hours later. All patients were placed on an aspirin regimen of $5 \mathrm{mg} / \mathrm{kg}$ for 6 months after the procedure. All patients had a chest radiograph, electrocardiogram, and echocardiogram at 24 hours, 1, 6, and 12 months after the procedure, and yearly thereafter.

The peratrial approach was used in 3 patients (patients 13, 14, and 15) owing to the size of the infant $(<3.5 \mathrm{~kg})$ in 2 cases and because of simultaneous perventricular ventricular septal defect (VSD) closure in 1 case (Figure 1). This approach involved a minimal lower sternotomy that was performed after full evaluation of the ASD by TEE. The right atrial wall was then punctured with an 18-gauge needle through which a 0.035 -inch wire was passed to the left atrium. The dilator and the introducing sheath were placed in the mid left atrium. Injecting agitated saline bubbles into the left atrium confirmed the position of the sheath. The ASO was then loaded into the sheath and the left disc was deployed first, followed by the right disc. The position of the device was then confirmed by TEE before the device was released.

\section{Statistical Analysis}

Values are given as mean \pm standard deviation and range.

\section{Results}

Table 1 demonstrates the clinical data of all 15 patients. There were 12 percutaneous and 3 peratrial (hybrid) procedures performed. Delivery of devices was successful in all except 1 patient (patient 12), in whom multiple attempts at deploying the device failed owing to deficient inferoposterior rim. The size of the ASD as measured by echocardiography (TEE or ICE) ranged from 2 to $16 \mathrm{~mm}(8.0 \pm 4.4$ $\mathrm{mm}$ ). One patient (patient 15 in Table 1) had a fenestrated ASD with one large ASD measuring $8 \mathrm{~mm}$ and a few smaller ones. There was a left-to-right shunt across the ASD in all patients. The pulmonary/systemic flow ratio ranged from 1.0 to $9.0(2.8 \pm 2.0)$. The size of the ASO device implanted ranged from 4 to $20 \mathrm{~mm}(10.1 \pm 4.3 \mathrm{~mm})$. The size of the sheaths used to release the device ranged from $5 \mathrm{~F}$ to $8 \mathrm{~F}$. In the 3 infants in whom ICE was used, an additional $8 \mathrm{~F}$ sheath was placed in the left femoral vein. In the percutaneous cases, the fluoroscopy time and the total procedure time ranged from 5.7 to 56.0 minutes $(20.5 \pm 13.8$ minutes $)$ and from 48.0 to 222.0 minutes (110.3 \pm 53.1 ), respectively. In those who had a successful attempt, the immediate 
complete closure rate was $92.9 \%$ overall $(90.9 \%$ in the percutaneous group and $100 \%$ in the peratrial group). At 24 hours, 2 of 14 patients in whom devices were deployed had small residual shunts. However, the closure rate was $100 \%$ at 12 months' follow-up after the procedure in both groups.

Additional interventional procedures were performed in 4 of 15 patients during the same session (patients 2, 8, 11, and 15). Those included patent ductus arteriosus coil occlusion $(\mathrm{n}=1)$, aortic balloon angioplasty for recoarctation $(\mathrm{n}=1)$, and muscular VSD closure $(\mathrm{n}=2)$. In addition, 1 patient (patient 6 in Table I) had an electrophysiologic study subsequent to the intervention because of a history of atrioventricular node re-entrant tachycardia. Cardiopulmonary bypass was not needed in any of the peratrial cases.

Table 1 also lists the adverse events related to the procedure or to the device. Minor complications were encountered in 3 patients. These included transient arrhythmias in 2 patients and blood loss during access requiring blood transfusion in 1 patient. One patient had a major complication (vascular intimal injury in the right femoral vein). This resulted in swelling of the right leg owing to thrombus formation in the femoral and iliac veins with extension into the inferior vena cava. This patient required heparin therapy for a few days followed by warfarin for 6 months. The swelling has disappeared; however, the inferior vena cava remains thrombosed. One patient who had Down syndrome died 6 weeks after the procedure of progressive pulmonary hypertension and right ventricular failure. All other 13 patients did well.
To date, there have been no episodes of endocarditis, thromboembolism, device disruption or erosion, valve regurgitation, or permanent rhythm disturbances.

\section{Follow-up and Clinical Condition}

The mean follow-up period was $3.2 \pm 1.9$ years (range 0.6-6.9 years). All children with feeding problems and failure to thrive gained weight and were above the 10th percentile for weight on last follow-up. All patients who were supported by mechanical ventilation were weaned from the ventilator shortly after device closure. In particular, the 2 premature patients with significant bronchopulmonary dysplasia were also successfully extubated within 10 days of the procedure. One patient (patient 5, Table I), who was born with critical aortic valve stenosis and somewhat marginal left ventricular size, initially underwent successful balloon aortic valvuloplasty. However, he continued to be ventilator-dependent with heart failure resulting from significant left-to-right shunt at the ASD level. He was successfully extubated within 24 hours after ASD closure in the catheterization laboratory and was discharged home in good condition. Another patient (patient 8) was status post surgical repair of severe coarctation of the aorta. However, he remained in heart failure owing to significant shunt via an ASD. After device closure, he was weaned off all medications and was discharged home. One patient with Down syndrome died in our series (patient 1). That patient was a $51 / 2$-month-old boy who had heart failure owing to a significant left-to-right shunt via the ASD. During the cardiac catheterization, the pulmonary artery pressure was elevated

TABLE 1. Clinical data of infants undergoing ASD closure

\begin{tabular}{|c|c|c|c|c|c|c|}
\hline $\begin{array}{l}\text { Patient } \\
\text { no. }\end{array}$ & $\begin{array}{l}\text { Age } \\
\text { (mo) }\end{array}$ & Gender & $\begin{array}{c}\text { Weight } \\
\text { (kg) }\end{array}$ & Diagnosis & Op/0s & $\begin{array}{c}\text { ASD size } \\
(\mathrm{mm})\end{array}$ \\
\hline 1 & 5.6 & M & 5.6 & Down syndrome, secundum ASD, pulmonary hypertension & 2.6 & 7.3 \\
\hline 2 & 10.9 & M & 4.0 & Secundum ASD, PDA, branch PA stenosis & 2.3 & 10.0 \\
\hline 3 & 7.8 & M & 5.8 & Alagille syndrome, PPS, PFO & 1.3 & 2.0 \\
\hline 4 & 11.5 & M & 8.3 & Secundum ASD & 2.4 & 15.0 \\
\hline 5 & 0.5 & M & 4.6 & Critical AS s/p angioplasty, PDA, secundum ASD & 9.0 & 9.0 \\
\hline 6 & 7.8 & $\mathrm{~F}$ & 6.9 & Secundum ASD, AVNRT & 1.5 & 5.0 \\
\hline 7 & 11.2 & $\mathrm{~F}$ & 7.2 & Secundum ASD & 2.0 & 12.0 \\
\hline 8 & 2.2 & M & 3.8 & $\begin{array}{l}\text { Coarctation of aorta s/p repair, subvalvular AS, bicuspid } \\
\text { AoV, small LV }\end{array}$ & 1.0 & 4.0 \\
\hline 9 & 7.9 & M & 5.1 & Secundum ASD & 2.7 & 12.0 \\
\hline 10 & 11.9 & $\mathrm{~F}$ & 7.0 & Secundum ASD & 2.3 & 14.8 \\
\hline 11 & 10.6 & $\mathrm{~F}$ & 6.5 & Secundum ASD, multiple mVSDs & 3.6 & 10.0 \\
\hline 12 & 10.1 & M & 7.5 & Down syndrome, secundum ASD & 2.3 & 16.0 \\
\hline 13 & 2.2 & M & 3.0 & BPD, secundum ASD & & 7.0 \\
\hline 14 & 3.1 & $\mathrm{~F}$ & 3.1 & BPD, secundum ASD & & 5.5 \\
\hline 15 & 3.4 & $\mathrm{~F}$ & 4.0 & Secundum ASD, mVSD & & $8.0,5.0,2.0$ \\
\hline
\end{tabular}


at near systemic levels with a pulmonary/systemic flow ratio of 2.6 and a pulmonary vascular resistance of 5.9 units in room air. We believed that closure of the ASD was indicated. The defect was closed completely with an 8-mm device. However, the patient continued to have right ventricular enlargement and the pulmonary artery pressure continued to increase as evaluated by the tricuspid regurgitation jet. Six weeks after closure, he died of severe heart failure. Autopsy revealed complete closure of the defect and that the device was far from vital structures (pulmonary veins, superior vena cava, and the atrioventricular valves). Histopathologic examination of the lungs revealed severe pulmonary vascular obstructive disease, consistent with HeathEdwards grade III-IV.

In addition, we evaluated the growth of the atrial septum in some of our patients as they grew (Figure 2). The ratio of the device to the atrial septum was calculated at the time of the procedure and then at 1-year follow-up with the 4-chamber apical view by transthoracic echocardiography. As is shown in Figure 2, there is a trend for this ratio to decrease as these infants grow older. Thus, although the device is significantly large compared with the atrial septum at the time of closure, the septum grows significantly and the device size becomes less concerning.

\section{Discussion}

Patients with secundum ASD are usually asymptomatic during the first few years of life. Occasionally, however, those patients are seen in infancy with signs and symptoms of congestive heart failure, ${ }^{13}$ frequent respiratory infec- tions, ${ }^{14}$ and failure to thrive. ${ }^{15}$ Although most centers advocate elective closure of moderate-to-large ASDs between 4 and 6 years of age, ${ }^{16,17}$ there is no general agreement on managing those patients who are referred in infancy, and significant debate remains as to the optimal timing as well as the mode of closure of ASDs in infancy. Although surgical closure of ASD has a low perioperative mortality and morbidity, it is still associated with a cosmetic disadvantage and a longer hospital stay compared with device closure. ${ }^{7}$ In addition, although atrial septal defects may close spontaneously during the first few years of life, ${ }^{18,19}$ some have been shown to enlarge with time. ${ }^{20}$ Therefore, we elected to study the efficacy and safety of device closure in those infants who are symptomatic or have other noncardiac indications for closure. To our knowledge, this is the largest series in the literature of infants undergoing device closure of secundum ASD.

Few clinical studies in the literature have addressed the problem of symptomatic secundum ASD in infants. Most are publications reporting on the outcome of surgical closure in small series of patients. ${ }^{15,21-24}$ A study by Parvathy and associates ${ }^{25}$ evaluated the outcomes of surgical closure of ASD in 18 children under 2 years of age. It showed encouraging results good enough that the group recommended early closure of ASD in symptomatic infants. In that study, 4 of 18 infants had pulmonary complications. Lammers and coworkers ${ }^{26}$ reported on the surgical closure of secundum ASD in 24 symptomatic infants less than 1 year of age and showed significant improvement in growth and development on follow-up of these patients, except for

TABLE 1. Continued

\begin{tabular}{|c|c|c|c|c|c|c|c|}
\hline $\begin{array}{l}\text { Device size } \\
\text { (mm) }\end{array}$ & $\begin{array}{c}\text { Additional interventional } \\
\text { procedures }\end{array}$ & Approach & $\begin{array}{c}\text { Sheath } \\
\text { (F) }\end{array}$ & $\begin{array}{c}\mathrm{FT} \\
(\mathrm{min})\end{array}$ & PT (min) & $\begin{array}{l}\text { Shunt by echo: Immediate/ } \\
24 \mathrm{~h} / 1 \mathrm{mo} / 1 \mathrm{y}\end{array}$ & Complications \\
\hline 8.0 & None & $\mathrm{PC}$ & & 20.5 & 120.0 & $\mathrm{C} / \mathrm{C}$ & Died \\
\hline 12.0 & PDA coil occlusion & PC & 7 & 18.0 & 105.0 & $\mathrm{C} / \mathrm{C} / \mathrm{C} / \mathrm{C}$ & Bleeding, transfused \\
\hline 4.0 & None & PC & 5 & 10.7 & 63.0 & $\mathrm{C} / \mathrm{C} / \mathrm{C} / \mathrm{C}$ & None \\
\hline 20.0 & None & PC & 8 & 20.6 & 96.0 & $\mathrm{C} / \mathrm{C} / \mathrm{C} / \mathrm{C}$ & None \\
\hline 11.0 & None & PC & 7 & 8.5 & 68.0 & $\mathrm{SS} / \mathrm{SS} / \mathrm{SS} / \mathrm{C}$ & None \\
\hline 5.0 & EP study & PC & 6 & 17.6 & 195.0 & $\mathrm{C} / \mathrm{C} / \mathrm{C} / \mathrm{C}$ & Arrhythmia, hypotension \\
\hline 12.0 & None & PC & 8 & 5.7 & 48.0 & $\mathrm{C} / \mathrm{SS} / \mathrm{C} / \mathrm{C}$ & None \\
\hline 6.0 & Aortic balloon angioplasty & PC & 5 & 22.5 & 107.0 & $\mathrm{C} / \mathrm{C} / \mathrm{C} / \mathrm{C}$ & None \\
\hline 13.0 & None & $\mathrm{PC}$ & 8 & 36.9 & 136.0 & $\mathrm{C} / \mathrm{C} / \mathrm{C} / \mathrm{C}$ & IVC intimal injury \\
\hline 14.0 & None & PC & 8 & 11.0 & 62.0 & $\mathrm{C} / \mathrm{C} / \mathrm{C} / \mathrm{C}$ & None \\
\hline 12.0 & 4 mVSD device closure & PC & 8 & 56.0 & 222.0 & $\mathrm{C} / \mathrm{C} / \mathrm{C} / \mathrm{C}$ & None \\
\hline NA & None & PC & 8 & 18.2 & 102.0 & $\mathrm{C} / \mathrm{C} / \mathrm{C} / \mathrm{C}$ & Surgical closure, none \\
\hline 7.0 & None & PA & 7 & & & $\mathrm{C} / \mathrm{C} / \mathrm{C} / \mathrm{C}$ & Intermittent heart block \\
\hline 6.0 & None & PA & 7 & & & $\mathrm{C} / \mathrm{C} / \mathrm{C} / \mathrm{C}$ & None \\
\hline 11.0 & mVSD device closure & PA & 7 & & & $\mathrm{C} / \mathrm{C} / \mathrm{C} / \mathrm{C}$ & None \\
\hline
\end{tabular}

$A S D$, Atrial septal defect; $Q p / Q s$, pulmonary/systemic flow ratio; $F T$, fluoroscopy time; $P T$, procedure time; $P C$, percutaneous; $C$, closed; $P D A$, patent ductus arteriosus; $P A$. peratrial; $P P S$, peripheral pulmonary stenosis; $A S$, aortic stenosis; $s / p$, status post; $S S$, small shunt; $A V N R T$, atrioventricular node re-entrant tachycardia; $E P$, electrophysiologic; $A o V$, aortic valve; $L V$, left ventricle; $I V C$, inferior vena cava; $m V S D$, muscular ventricular septal defect; $B P D$, bronchopulmonary dysplasia. 

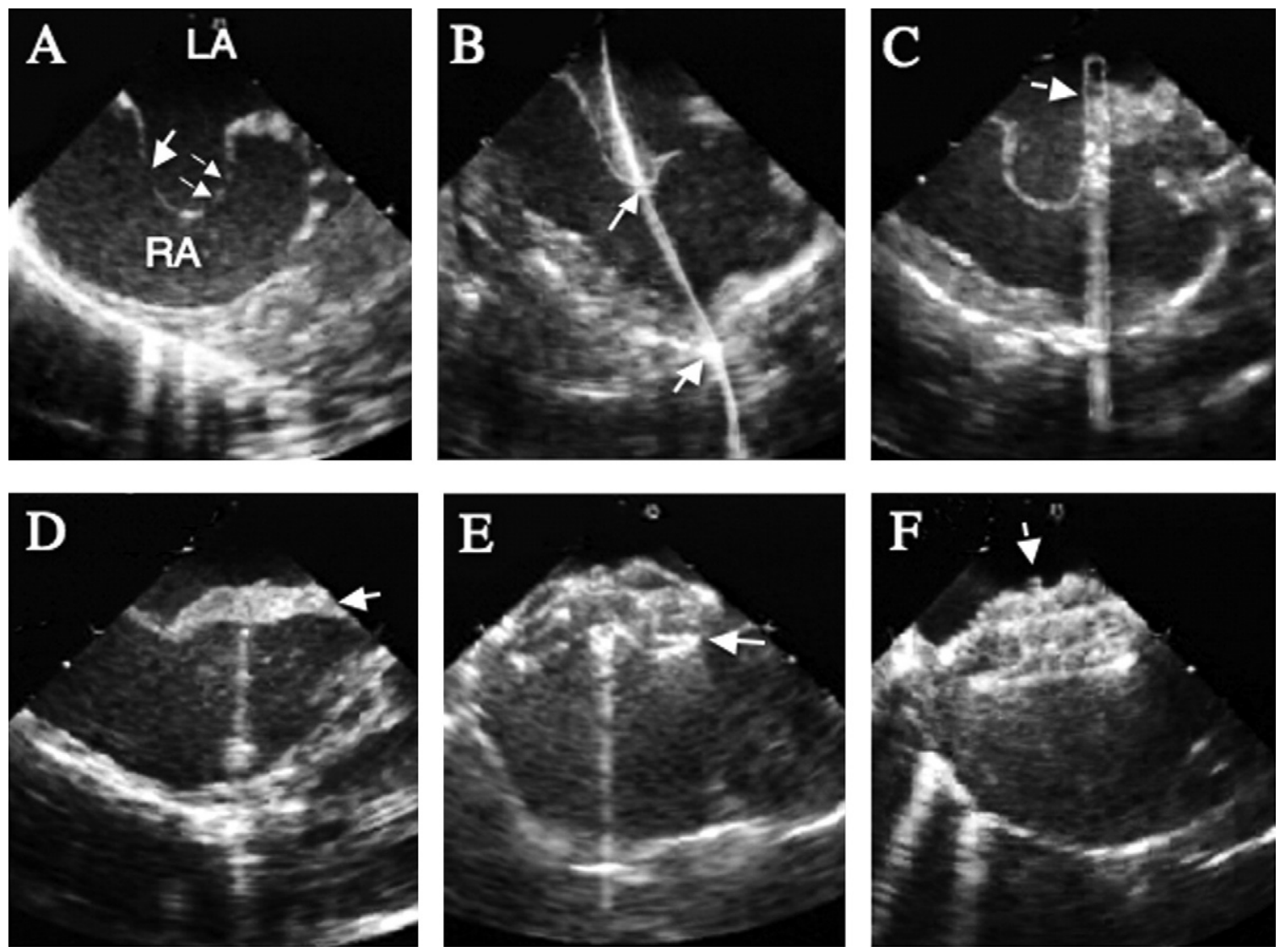

Figure 1. TEE images in a 3.4-month-old infant who underwent peratrial atrial septal defect (ASD) device closure. A, Aneurysmal atrial septum with a large 8-mm defect (large arrow) and smaller fenestrations (small arrows). B, Guide wire passing through the right atrial free wall (large arrow) and across the defect (small arrow). C, Short delivery sheath positioned from the right atrial free wall into the left atrial cavity across the ASD. D, The left disc of an 11-mm Amplatzer septal occluder (ASO) is deployed in the left atrial cavity (arrow). E, Connecting waist and right atrial disc (arrow) deployed. F, Final image after both discs were deployed demonstrating good device position. TEE, transesophageal echocardiographic; $L A$, Left atrium; $R A$, right atrium.

1 infant with Down syndrome who died later of severe pulmonary hypertension. More recently, a study by Vogel and colleagues ${ }^{27}$ reported the results of percutaneous closure of secundum ASD in 12 symptomatic patients less than 2 years of age with a mean age of $1.5 \pm 0.4$ (range 0.8-1.8 years) using the ASO device. Only 5 of 12 patients in that study weighed less than $10 \mathrm{~kg}$. Although that study showed that the procedure could be successfully achieved, the success rates were lower than in older patients and 2 patients needed the device to be removed surgically due to continued large residual shunt.

In our series, device closure was successful in 14 of 15 patients. In 1 patient in whom TEE showed possible appropriate rims for device closure, ICE documented deficient inferoposterior rims; device closure was unsuccessful despite multiple attempts owing to prolapse of the device into the right atrium. The patient underwent surgical closure with no complications. In those who had a successful attempt, closure rates were very encouraging: $86 \%$ at 24 hours and $100 \%$ at 1-year follow-up. This result compares favorably with closure rates of $98.5 \%$ at 1-year follow-up reported in older children and adults. ${ }^{7}$ In 1 patient, the device prolapsed through the defect and a larger sheath was needed to recapture the device and to implant a larger size occluder. Only 1 patient had a technical difficulty, in which the device could not be seated well owing to a deficient inferior rim; the device was recaptured and the patient was sent for surgical closure at a later date.

In our patients, $5 \mathrm{~F}$ to $8 \mathrm{~F}$ sheaths were used to deliver the ASO devices. In 2 patients, a 5F sheath was used and in 5 others an $8 \mathrm{~F}$ sheath was required. Only 1 patient, in whom an $8 \mathrm{~F}$ sheath was used to deliver a $13-\mathrm{mm}$ device (delivered with an $8 \mathrm{~F}$ Judkins right coronary guide catheter to prevent prolapse of the left atrial disc into the right atrium), had a 


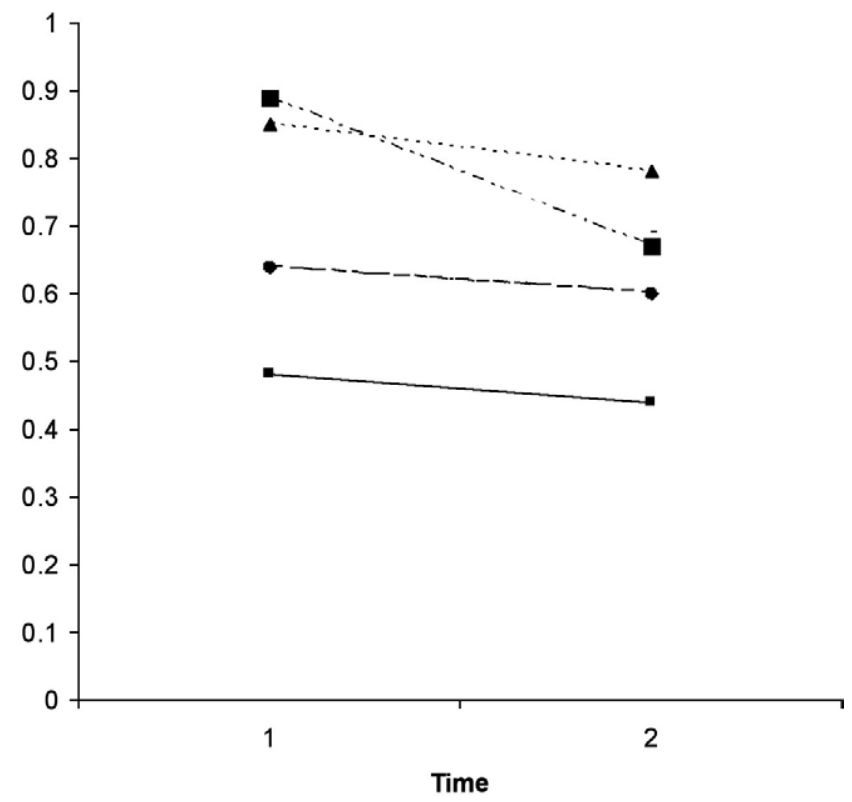

Figure 2. Graph showing the growth of the atrial septum in some of our patients at time of procedure (point 1) and at 1 year follow-up (point 2). The ratio of the device to the atrial septum was calculated with the 4-chamber apical view by transthoracic echocardiography.

vascular complication with injury to the intima of the inferior vena cava (see above).

In the percutaneous cases, the ASO was delivered through femoral access in 10 instances. In 1 patient (patient 8 ) in whom both femoral veins were thrombosed, the transhepatic approach was used to deliver a 6-mm ASO device with no complications.

In most of our patients, ASD closure was done routinely under TEE guidance. ICE was used in 3 patients with no complications (patients 10,11, and 12). It has been shown in previous reports that ICE provided better imaging for secundum ASD and the left atrium and that its use as a guiding imaging tool for device closure resulted in no significant adverse events in patients weighing less than 15 $\mathrm{kg} .{ }^{4}$ In the patient in whom device closure was unsuccessful (patient 12), we believe ICE was superior to TEE in delineating the rims of the defect, especially the inferoposterior rims, to guide device closure.

The peratrial (hybrid) technique was used in 3 infants in our series. The advantage of this approach compared with the classic surgical approach is avoidance of cardiopulmonary bypass that could be associated with significant morbidity in premature patients with severe bronchopulmonary dysplasia (2 patients in this series). In addition, unlike the percutaneous technique, the peratrial approach provides some advantages: it preserves the fem- oral vessels and provides a perpendicular angle to the atrial septum as opposed to the sharp angle through the IVC as in the transcatheter closure, which may result in prolapse of the left atrial disc into the right atrium. The hybrid approach rather than the percutaneous approach was used in these cases owing to the size of the infants $(<3.5 \mathrm{~kg})$ in 2 patients and because of the simultaneous perventricular muscular VSD closure in 1 patient. All 3 patients had complete closure immediately after device implantation and at 1-year follow-up.

This series demonstrates encouraging results with an acceptable incidence of complications related to the procedure or device implantation. Only 1 patient died in our series, and his death was not procedure or device related. That patient clearly met the criteria to close the defect; however, perhaps a fenestrated device would have been a better consideration.

Minor complications occurred in 3 of 14 (21.4\%) patients in our study, 2 of which were related to transient arrhythmias. This is higher than the rate of minor morbidity of $17.8 \%$ reported with surgical closure and of $7.2 \%$ reported with device closure in older children and adults. ${ }^{3}$ One of these patients who had arrhythmia, however, was known to have atrioventricular node re-entrant tachycardia. One patient who underwent peratrial device closure (patient 13) had transient heart block during device manipulation and it resolved at the end of the procedure.

Device embolization was not encountered in our series. The risk for this complication was reported to be about $1.1 \%$. We believe that more experience in using the ASO device in young infants will make this technical complication less frequent. It is important to mention, however, that the ability to retrieve the device might be more challenging in infants, especially that large sheaths would be required.

Last, as mentioned earlier, all infants thrived well after device closure and their weight was above the 10th percentile on the latest follow-up, proving that these defects were the cause for the failure to thrive.

\section{Study Limitation}

Like any retrospective study, there is bias associated with data collection and the incomplete data of some patients. Although this report presents the largest series in the literature of infants less than 1 year of age undergoing device closure of secundum ASD, the number of patients included is still relatively small, particularly those patients undergoing peratrial closure, because this is not a commonly encountered indication. In addition, longer follow-up is still needed to determine the long-term safety of device closure in these patients. 


\section{Conclusions}

Our results demonstrate that device closure of ASDs is an effective and fairly safe alternative to surgery in infants. Peratrial closure is also an effective alternative approach to percutaneous closure in very small infants and allows avoidance of cardiopulmonary bypass. Closure of ASDs should not be postponed to older age in those infants who are symptomatic despite medical therapy. The long-term safety of this procedure is still to be determined as these children continue to grow.

\section{References}

1. Dickinson DF, Arnold R, Wilkinson JL. Congenital heart disease among 160,480 live-born children in Liverpool 1960 to 1969. Implications for surgical treatment. Br Heart J. 1981;46:55-62.

2. King TD, Thompson SL, Steiner C, Mills NL. Secundum atrial septal defect. Nonoperative closure during cardiac catheterization. JAMA. 1976;235:2506-9.

3. Masura J, Gavora P, Formanek A, Hijazi ZM. Transcatheter closure of secundum atrial septal defects using the new self-centering Amplatzer septal occluder: initial human experience. Cathet Cardiovasc Diagn. 1997;42:388-93.

4. Thanopoulos BD, Laskari CV, Tsaousis GS, Zarayelyan A, Vekiou A, Papadopoulos GS. Closure of atrial septal defects with the Amplatzer occlusion device: preliminary results. J Am Coll Cardiol. 1998;31: $1110-6$.

5. Hijazi ZM, Cao Q, Patel HT, Rhodes J, Hanlon KM. Transesophageal echocardiographic results of catheter closure of atrial septal defect in children and adults using the Amplatzer device. Am J Cardiol. 2000; 85:1387-90.

6. Cao QL, Radtke W, Berger F, Zhu W, Hijazi ZM. Transcatheter closure of multiple atrial septal defects. Initial results and value of two- and three-dimensional transoesophageal echocardiography. Eur Heart J. 2000;21:941-7.

7. Du ZD, Hijazi ZM, Kleinman CS, Silverman NH, Larntz K, for the Amplatzer Investigators. Comparison between transcatheter and surgical closure of secundum atrial septal defect in children and adults: results of a multicenter nonrandomized trial. J Am Coll Cardiol. 2002;39:1836-44.

8. Berger F, Vogel M, Alexi-Meskishvili V, Lange PE. Comparison of results and complications of surgical and Amplatzer device closure of atrial septal defects. J Thorac Cardiovasc Surg. 1999;118:674-8.

9. Kim JJ, Hijazi ZM. Clinical outcomes and costs of Amplatzer transcatheter closure as compared with surgical closure of ostium secundum atrial septal defects. Med Sci Monit. 2002;8:CR787-91.
10. Carminati M, Chessa M, Butera G, Bini RM, Giusti S, Festa P, et al. Transcatheter closure of atrial septal defects with the STARFlex device: early results and follow-up. J Interv Cardiol. 2001;14:319-24.

11. Chessa M, Carminati M, Butera G, Bini RM, Drago M, Rosti L, et al. Early and late complications associated with transcatheter occlusion of secundum atrial septal defect. J Am Coll Cardiol. 2002;39:1061-5.

12. Patel A, Cao QL, Koenig PR, Hijazi ZM. Intracardiac echocardiography to guide closure of atrial septal defects in children less than 15 kilograms. Catheter Cardiovasc Interv. 2006;68:287-91.

13. Phillips SJ, Okies JE, Henken D, Sunderland CO, Starr A. Complex of secundum atrial septal defect and congestive heart failure in infants. J Thorac Cardiovasc Surg. 1975;70:696-700.

14. Hunt CE, Lucas RV Jr. Symptomatic atrial septal defect in infancy. Circulation. 1973;47:1042-8.

15. Dimich I, Steinfeld L, Park SC. Symptomatic atrial septal defect in infants. Am Heart J. 1973;85:601-4.

16. Murphy JG, Gersh BJ, McGoon MD, Mair DD, Porter CJ, Ilstrup DM, et al. Long-term outcome after surgical repair of isolated atrial septal defect. Follow-up at 27 to 32 years. N Engl J Med. 1990;323:1645-50.

17. Black MD, Freedom RM. Minimally invasive repair of atrial septal defects. Ann Thorac Surg. 1998;65:765-7.

18. Helgason H, Jonsdottir G. Spontaneous closure of atrial septal defects. Pediatr Cardiol. 1999;20:195-9.

19. Radzik D, Davignon A, van Doesburg N, Fournier A, Marchand T, Ducharme G. Predictive factors for spontaneous closure of atrial septal defects diagnosed in the first 3 months of life. J Am Coll Cardiol. 1993;22:851-3.

20. McMahon CJ, Feltes TF, Fraley JK, Bricker JT, Grifka RG, Tortoriello TA, et al. Natural history of growth of secundum atrial septal defects and implications for transcatheter closure. Heart. 2002;87:256-9.

21. Bull C, Deanfield J, de Leval M, Stark J, Taylor JF, Macartney FJ. Correction of isolated secundum atrial septal defect in infancy. Arch Dis Child. 1981;56:784-6.

22. Spangler JG, Feldt RH, Danielson GK. Secundum atrial septal defect encountered in infancy. J Thorac Cardiovasc Surg. 1976;71:398-401.

23. Andrews R, Tulloh R, Magee A, Anderson D. Atrial septal defect with failure to thrive in infancy: hidden pulmonary vascular disease? Pediatr Cardiol. 2002;23:528-30.

24. Mainwaring RD, Mirali-Akbar H, Lamberti JJ, Moore JW. Secundumtype atrial septal defects with failure to thrive in the first year of life. J Card Surg. 1996;11:116-20.

25. Parvathy U, Balakrishnan KR, Ranjith MS, Saldanha R, Vakamudi M. Surgical closure of atrial septal defect in children under two years of age. Asian Cardiovasc Thorac Ann. 2004;12:296-9.

26. Lammers A, Hager A, Eicken A, Lange R, Hauser M, Hess J. Need for closure of secundum atrial septal defect in infancy. $J$ Thorac Cardiovasc Surg. 2005;129:1353-7.

27. Vogel M, Berger F, Dahnert I, Ewert P, Lange PE. Treatment of atrial septal defects in symptomatic children aged less than 2 years of age using the Amplatzer septal occluder. Cardiol Young. 2000;10:534-7. 